\title{
Comprehensive men's health and male infertility
}

\author{
Jeremy T. Choy ${ }^{1}$ Michael L. Eisenberg ${ }^{2}$ \\ ${ }^{1}$ Division of Endocrinology, Gerontology, and Metabolism, ${ }^{2}$ Department of Urology, Stanford University School of Medicine, Stanford, CA, USA \\ Contributions: (I) Conception and design: All authors; (II) Administrative support: All authors; (III) Provision of study materials or patients: None; \\ (IV) Collection and assembly of data: None; (V) Data analysis and interpretation: None; (VI) Manuscript writing: All authors; (VII) Final approval of \\ manuscript: All authors. \\ Correspondence to: Michael L. Eisenberg, MD. Department of Urology, Stanford University School of Medicine, 300 Pasteur Drive, Stanford, CA \\ 94305-5118, USA. Email: eisenberg@stanford.edu.
}

\begin{abstract}
There is increasing evidence that male infertility may be a harbinger of comorbid medical illness. Existing studies have shed light on associations between infertility and the prevalence of cardiovascular, metabolic, and oncologic disease, along with rates of hospitalization and overall mortality. Although theorized mechanisms include genetic, developmental, and behavioral precipitants, the exact nature of these associations remains unclear and warrants further investigation.
\end{abstract}

Keywords: Male infertility; men's health; spermatogenesis; mortality

Submitted Jun 08, 2019. Accepted for publication Aug 21, 2019.

doi: $10.21037 /$ tau.2019.08.35

View this article at: http://dx.doi.org/10.21037/tau.2019.08.35

\section{Introduction}

Infertility, or the inability to conceive after one year of unprotected intercourse, is thought to affect approximately $15 \%$ of couples worldwide (1). Twenty percent of these cases are due to male infertility alone, while $30 \%$ arise from a combination of male and female infertility factors $(2,3)$. Recent studies have begun to shed light on associations between male infertility and other medical comorbidities, although the exact mechanisms behind these associations remain elusive. The goal of his article is to review the existing literature supporting these associations and to consider various hypothesized factors which may be driving them.

\section{Male infertility and comorbid medical disease}

A recent large scale study comparing 3,328 infertile men in Japan with 452 fertile male controls showed that the prevalence of medical comorbidities was significantly higher in the infertile men (21.7\% versus $9.1 \%$ respectively), and further demonstrated that treatment of medical comorbidities effected a significant improvement in total motile sperm count over baseline and over men with untreated comorbidities (4). Concerning the comorbidities involved, the study found the highest prevalences were hypertension (17.8\%) and hyperlipidemia (5.9\%). An alternate cross-sectional study of over 9,000 men noted increasing comorbidity indices seen with decreases in sperm concentration, motility, and seminal volume, with comorbid hypertension, cardiac disease, and peripheral vascular disease being chiefly associated with these seminal parameter impairments (5). Indeed, there has been much prior work that points to associations between male infertility and both cardiovascular disease and metabolic disease. Hypertensive men have been found to have lower testosterone levels compared to their normotensive counterparts $(6,7)$, and one study in particular demonstrated lower semen volume, sperm count, and sperm motility in hypertensive patients (8). There are additional studies focusing on cardiovascular disease which have used imperfect surrogate variables for infertility; for example, a 2011 investigation utilizing data from the NIH-AARP Diet and Health Study demonstrated that men who had not fathered children had an increased risk of cardiovascular mortality during the approximately decade-long study period, although notably in this scenario, childlessness did not necessarily connote infertility (9). Another more recent study showed that men diagnosed with 
infertility had a higher likelihood of developing ischemic cardiac disease compared to fertile men (10).

Other studies have assessed the link between male infertility and metabolic disease. Epidemiologists have reported a worldwide deterioration of semen quality over the past 50 years (11), which has coincided with the growing obesity pandemic. Obesity itself has been associated with increased rates of oligospermia and azoospermia with a J-shaped association noted between body mass index (BMI) and risk of sperm concentration impairment (12), while hypercholesterolemia has been associated with impairments in sperm morphology (13). Men diagnosed with infertility have been found to be at an increased risk of developing diabetes mellitus (10), and conversely, an increased risk of infertility has been found amongst diabetic men (14).

There also exists an impressive body of literature connecting male infertility with oncologic disease. Multiple studies have reported a link between infertility and testicular cancer. One large scale study of 32,000 men over 30 years in Denmark detected an association between impaired sperm concentration, motility, and morphology with testicular cancer (15), while another study of 51,000 infertile couples in the US demonstrated a threefold increased risk of testicular cancer associated with male infertility (16). Oncologic risk does not seem to be limited to testicular cancer, as a 2013 American study which used insurance claims to identify a group of 76,000 infertile men also found elevated rates of all cancer types, and specifically nonHodgkin's lymphoma, in the infertile men as compared to controls (17). The data surrounding infertility and prostate cancer is far more muddled, with conflicting studies having previously reported increased risk, decreased risk, and no detectable association between prostate cancer and male infertility (18-20).

\section{Male infertility and mortality}

Male infertility has also been implicated as a harbinger of hospitalization. A study out of Denmark looking at 4,712 men who had presented for infertility workup concluded that impairments in sperm concentration and motility correlated with increased hospitalization rates (21). Furthermore, as the scope of investigation has expanded to assess a potential relationship between infertility and mortality, a Danish study of the semen analyses of 43,000 infertile men found mortality to decrease as sperm motility, morphology, and concentration increased, with up to a limit of 40 million sperm per milliliter in the case of the latter parameter (22). Meanwhile, an American study of 11,935 infertile men showed that decreased sperm motility, concentration, and seminal volume correlated with increased mortality rates, and also that men with at least two deficiencies in seminal parameters had a 2.3 -fold higher mortality risk (23).

\section{Potential associative etiologies}

While the exact mechanisms governing the relationship between male infertility and medical comorbidity remain unclear, multiple hypotheses have arisen to account for the apparent associations. The first is a genetic etiology, with a fertility impairing mutation having a potential downstream effect giving rise to other disease processes. Multiple examples of this phenomenon have already been noted, including CFTR mutations which result in cystic fibrosis along with the fertility-impairing congenital bilateral absence of the vas deferens (24), MLH1 mutations which cause both Lynch syndrome and nonobstructive azoospermia (25), and ERCC1 and MSH2 mutations which can give rise to colorectal cancer in addition to nonobstructive azoospermia (26-29). Most notably, Klinefelter syndrome, resulting from aneuploidy of sex chromosomes, is known to effect primary hypogonadism, while also conferring an increased risk of cardiovascular disease, diabetes mellitus, and various cancers (30-32). Additionally, Y chromosomal microdeletions can cause severe fertility impairment, and in some cases, contribute to short stature by way of involvement of the SHOX gene (33). In addition to isolated gene mutations, emerging data also suggests that aberrant epigenetic changes may give rise to sperm abnormalities and infertility, as studies have identified altered epigenetic profiles in the sperm of oligospermic men (34).

An alternative associative theory is based upon the theorized testicular dysgenesis syndrome, which links seminal parameter impairment with other genitourinary pathologies including cryptorchidism, hypospadias, and testicular cancer, and suggests that an inciting event during embryogenesis could be responsible for disrupted gonadal development and may promote the development of other disease processes later in life (35). Implicated precipitants may include environmental factors and assisted reproductive technologies (36). Indeed, certain studies have shown that IVF/ICSI (in vitro fertilization/ intracytoplasmic sperm injection)-conceived babies tend 
to have higher rates of hypospadias, cryptorchidism, and preterm birth, the latter of which predisposes them to the development of cardiovascular disease and diabetes (37-39). ICSI-conceived males have also been found to have lower sperm concentrations and counts as compared to naturally conceived controls (40).

Finally, lifestyle or psychosocial variables have been suspected to play a role in the association between infertility and comorbidity. While the data linking infertility and obesity, itself a predisposing factor to other chronic illness, have been previously discussed, noxious behaviors such as tobacco and alcohol overuse can also have negative effects on both general health and fertility. Through a meta-analysis, smoking has been shown to contribute to impairments in sperm concentration, motility, morphology, and semen volume (41). The data surrounding alcohol abuse is more equivocal, however, with some studies noting alcohol-associated reduction in semen volume, while others have noted no adverse effects of moderate alcohol intake on seminal parameters or conception rates $(42,43)$. Even psychological stress has been found to negatively impact sperm concentration, morphology, and motility (41).

\section{Conclusions}

The existing body of literature has highlighted an apparent relationship between male infertility and other systemic pathologies, including cardiovascular, metabolic, and oncologic disease. While genetic, developmental, and psychosocial catalysts have been recognized, there is still much investigative work to be done to further identify and elucidate the mechanistic drivers behind the association between infertility and medical comorbidity. As fertility impairment could potentially serve as a biomarker of health, providing clinicians with preventive insight into the development or progression of other chronic diseases, a better understanding of these associations would be paramount to promoting the optimal care of a man's overall health.

\section{Acknowledgments}

Funding: None.

\section{Footnote}

Provenance and Peer Review: This article was commissioned by the Guest Editors (Larry I. Lipshultz, Alexander W.
Pastuszak) for the focused issue "Contemporary Issues and Controversies in Men's Health" published in Translational Andrology and Urology. The article was sent for external peer review organized by the Guest Editors and the editorial office.

Conflicts of Interest: The focused issue "Contemporary Issues and Controversies in Men's Health" was commissioned by the editorial office without any funding or sponsorship. ML Eisenberg: advisor to Sandstone Diagnostics, Dadi, Ro; JT Choy has no conflicts of interest to declare.

Ethical Statement: The authors are accountable for all aspects of the work in ensuring that questions related to the accuracy or integrity of any part of the work are appropriately investigated and resolved.

Open Access Statement: This is an Open Access article distributed in accordance with the Creative Commons Attribution-NonCommercial-NoDerivs 4.0 International License (CC BY-NC-ND 4.0), which permits the noncommercial replication and distribution of the article with the strict proviso that no changes or edits are made and the original work is properly cited (including links to both the formal publication through the relevant DOI and the license). See: https://creativecommons.org/licenses/by-nc$\mathrm{nd} / 4.0 /$.

\section{References}

1. Zegers-Hochschild F, Adamson GD, de Mouzon J, et al. International Committee for Monitoring Assisted Reproductive Technology (ICMART) and the World Health Organization (WHO) revised glossary of ART terminology, 2009. Fertil Steril 2009;92:1520-4.

2. Thoma ME, McLain AC, Louis JF, et al. Prevalence of infertility in the United States as estimated by the current duration approach and a traditional constructed approach. Fertil Steril 2013;99:1324-31.e1.

3. Practice Committee of the American Society for Reproductive Medicine. Diagnostic evaluation of the infertile male: a committee opinion. Fertil Steril 2015;103:e18-25.

4. Shiraishi K, Matsuyama H. Effects of medical comorbidity on male infertility and comorbidity treatment on spermatogenesis. Fertil Steril 2018;110:1006-11.e2.

5. Eisenberg ML, Li S, Behr B, et al. Relationship between semen production and medical comorbidity. Fertil Steril 
2015;103:66-71.

6. Svartberg J, von Muhlen D, Schirmer H, et al. Association of endogenous testosterone with blood pressure and left ventricular mass in men. The Tromso Study. Eur J Endocrinol 2004;150:65-71.

7. Fogari R, Zoppi A, Preti P, et al. Sexual activity and plasma testosterone levels in hypertensive males. Am J Hypertens 2002;15:217-21.

8. Guo D, Li S, Behr B, et al. Hypertension and Male Fertility. World J Mens Health 2017;35:59-64.

9. Eisenberg ML, Park Y, Hollenbeck AR, et al. Fatherhood and the risk of cardiovascular mortality in the NIH-AARP Diet and Health Study. Hum Reprod 2011;26:3479-85.

10. Eisenberg ML, Li S, Cullen MR, et al. Increased risk of incident chronic medical conditions in infertile men: analysis of United States claims data. Fertil Steril 2016;105:629-36.

11. Merzenich H, Zeeb H, Blettner M. Decreasing sperm quality: a global problem? BMC Public Health 2010;10:24.

12. Sermondade N, Faure C, Fezeu L, et al. BMI in relation to sperm count: an updated systematic review and collaborative meta-analysis. Hum Reprod Update 2013;19:221-31.

13. Schisterman EF, Mumford SL, Chen Z, et al. Lipid concentrations and semen quality: the LIFE study. Andrology 2014;2:408-15.

14. Bener A, Al-Ansari AA, Zirie M, et al. Is male fertility associated with type 2 diabetes mellitus? Int Urol Nephrol 2009;41:777-84.

15. Jacobsen R, Bostofte E, Engholm G, et al. Risk of testicular cancer in men with abnormal semen characteristics: cohort study. BMJ 2000;321:789-92.

16. Walsh TJ, Croughan MS, Schembri M, et al. Increased risk of testicular germ cell cancer among infertile men. Arch Intern Med 2009;169:351-6.

17. Eisenberg ML, Betts P, Herder D, et al. Increased risk of cancer among azoospermic men. Fertil Steril 2013;100:681-5.

18. Walsh TJ, Schembri M, Turek PJ, et al. Increased risk of high-grade prostate cancer among infertile men. Cancer 2010;116:2140-7.

19. Hanson BM, Eisenberg ML, Hotaling JM. Male infertility: a biomarker of individual and familial cancer risk. Fertil Steril 2018;109:6-19.

20. Ruhayel Y, Giwercman A, Ulmert D, et al. Male infertility and prostate cancer risk: a nested case-control study.

Cancer Causes Control 2010;21:1635-43.

21. Latif T, Lindahl-Jacobsen R, Mehlsen J, et al. Semen quality associated with subsequent hospitalizations - Can the effect be explained by socio-economic status and lifestyle factors? Andrology 2018;6:428-35.

22. Jensen TK, Jacobsen R, Christensen K, et al. Good semen quality and life expectancy: a cohort study of 43,277 men. Am J Epidemiol 2009;170:559-65.

23. Eisenberg ML, Li S, Behr B, et al. Semen quality, infertility and mortality in the USA. Hum Reprod 2014;29:1567-74.

24. Claustres M. Molecular pathology of the CFTR locus in male infertility. Reprod Biomed Online 2005;10:14-41.

25. Sun F, Turek P, Greene C, et al. Abnormal progression through meiosis in men with nonobstructive azoospermia. Fertil Steril 2007;87:565-71.

26. Li P, Xiao Z, Braciak TA, et al. Systematic immunohistochemical screening for mismatch repair and ERCC1 gene expression from colorectal cancers in China: Clinicopathological characteristics and effects on survival. PLoS One 2017;12:e181615.

27. Zhao L. Mismatch repair protein expression in patients with stage II and III sporadic colorectal cancer. Oncol Lett 2018;15:8053-61.

28. Paul C, Povey JE, Lawrence NJ, et al. Deletion of genes implicated in protecting the integrity of male germ cells has differential effects on the incidence of DNA breaks and germ cell loss. PLoS One 2007;2:e989.

29. Reitmair AH, Schmits R, Ewel A, et al. MSH2 deficient mice are viable and susceptible to lymphoid tumours. Nat Genet 1995;11:64-70.

30. Salzano A, D'Assante R, Heaney LM, et al. Klinefelter syndrome, insulin resistance, metabolic syndrome, and diabetes: review of literature and clinical perspectives. Endocrine 2018;61:194-203.

31. Weiss JR, Moysich KB, Swede H. Epidemiology of male breast cancer. Cancer Epidemiol Biomarkers Prev 2005; 14:20-6.

32. Swerdlow AJ, Schoemaker MJ, Higgins CD, et al. Cancer incidence and mortality in men with Klinefelter syndrome: a cohort study. J Natl Cancer Inst 2005;97:1204-10.

33. Jorgez CJ, Weedin JW, Sahin A, et al. Aberrations in pseudoautosomal regions (PARs) found in infertile men with Y-chromosome microdeletions. J Clin Endocrinol Metab 2011;96:E674-9.

34. Dada R, Kumar M, Jesudasan R, et al. Epigenetics and its role in male infertility. J Assist Reprod Genet 2012;29:213-23.

35. Skakkebaek NE, Rajpert-De Meyts E, Main KM. Testicular dysgenesis syndrome: an increasingly common 
developmental disorder with environmental aspects. Hum Reprod 2001;16:972-8.

36. Skakkebaek NE, Rajpert-De Meyts E, Buck Louis GM, et al. Male Reproductive Disorders and Fertility Trends: Influences of Environment and Genetic Susceptibility. Physiol Rev 2016;96:55-97.

37. Bang JK, Lyu SW, Choi J, et al. Does infertility treatment increase male reproductive tract disorder? Urology 2013;81:644-8.

38. Posod A, Odri Komazec I, Kager K, et al. Former Very Preterm Infants Show an Unfavorable Cardiovascular Risk Profile at a Preschool Age. PLoS One 2016;11:e0168162.

39. Bloomfield FH. Impact of prematurity for pancreatic islet and beta cell development. J Endocrinol 2018;238:R161-71.

Cite this article as: Choy JT, Eisenberg ML. Comprehensive men's health and male infertility. Transl Androl Urol 2020;9(Suppl 2):S239-S243. doi: 10.21037/tau.2019.08.35
40. Belva F, Bonduelle M, Roelants M, et al. Semen quality of young adult ICSI offspring: the first results. Hum Reprod 2016;31:2811-20.

41. Li Y, Lin H, Li Y, et al. Association between socio-psychobehavioral factors and male semen quality: systematic review and meta-analyses. Fertil Steril 2011;95:116-23.

42. Jensen TK, Hjollund NH, Henriksen TB, et al. Does moderate alcohol consumption affect fertility? Follow up study among couples planning first pregnancy. BMJ 1998;317:505-10.

43. Jensen TK, Swan S, Jorgensen N, et al. Alcohol and male reproductive health: a cross-sectional study of 8344 healthy men from Europe and the USA. Hum Reprod 2014;29:1801-9. 